\title{
"You look a little bit dark for my liking": Māori and Pasifika women's experiences of welfare receipt in Aotearoa New Zealand
}

Claire Gray and Yvonne Crichton-Hill, University of Canterbury, New Zealand

\begin{abstract}
INTRODUCTION: Based on empirical research with Māori and Pasifika lone mothers, this article considers the way that discourses of ethnicity and welfare combine to shape the lived experience of welfare receipt.
\end{abstract}

METHOD: Drawing from 16 focus groups and interviews conducted in 2014 throughout Aotearoa New Zealand with women receiving Sole Parent Support, we analyse the way participants spoke of their experiences with Work and Income New Zealand.

FINDINGS: Our findings indicate that the negative experiences related to the receipt of welfare in New Zealand are intensified for women who identify ethnically as Māori or Pasifika. Many of the women who took part in the research attributed poor treatment, including the denial of access to welfare entitlements, to their ethnicity. Participants spoke of avoiding visits to welfare offices because of the racism they anticipated experiencing in these spaces.

CONCLUSIONS: There are significant implications for these findings. We argue that identifying as Māori or Pasifika can have consequences in relation to accessing welfare entitlements and that ethnicity may negatively influence interactions within welfare offices in Aotearoa New Zealand.

This article analyses accounts of Māori and Pasifika lone mothers as they discussed their experiences of welfare receipt. ${ }^{1}$ Empirical research carried out by the first author with lone mothers receiving welfare has drawn attention to the many adverse experiences associated with the receipt of welfare, particularly in relation to interactions with welfare case workers (Gray, 2017). In this article, we specifically examine accounts of Māori and Pasifika participants who took part in this research as they described their experiences at Work and Income New Zealand (hereafter Work and Income). Work and Income is the national provider of welfare services in New Zealand and is part of the Ministry of Social Development (MSD).
Figures from the ministry indicate that $48 \%$ of recipients of Sole Parent Support - a welfare benefit paid to single parents with one or more dependent children aged 14 years or younger - identify as Māori, 11\% as Pasifika and $30 \%$ as Pākehā (MSD, 2017).

In this article, we argue that negative experiences related to the collection of welfare are amplified for non-Pākehā women. Our analysis of the experiences of Māori and Pasifika women sits within the broader context of racism in this country. New Zealand is a society shaped by the legacy of colonisation where outcomes for Māori and Pasifika people are generally far less positive than for Pākehā (Marriott \&
AOTEAROA

NEW ZEALAND SOCIAL WORK 31(1), 5-16.

CORRESPONDENCE TO: Claire Gray

clairegrayresearch@gmail.com 
Sim, 2015). During the 2013 census, 17.5\% of the New Zealand population identified as Māori and 7.4\% identified with one or more Pasifika ethnic groups from the Cook Islands, Niue, Tokelau, Samoa or Tonga (Statistics New Zealand, 2014). Overt discrimination against Māori and Pasifika people in New Zealand is well documented (Marriott \& Sim, 2015; Pack, Tuffin, \& Lyons, 2016). Māori and Pasifika people in this country are disproportionately represented in all negative statistics related to health, employment and poverty (Statistics New Zealand, 2014). ${ }^{2}$ People within these ethnic groupings have lower workforce participation, and poverty rates are around double those of Pākehā (Marriott \& Sim, 2015). A Ministry of Health report released in 2015 found that, between 2011 and 2012, $12.4 \%$ of Māori described experiencing unfair treatment in the areas of health care, housing or work, compared to $4.2 \%$ of non-Māori (Ministry of Health, 2015). This finding aligns with an earlier Statistics New Zealand report that found nearly $10 \%$ of Māori and Pasifika people reported experiencing racial discrimination in the previous 12 months (Statistics New Zealand, 2012).

In 1986, the Ministerial Advisory Committee on a Maori Perspective for the Department of Social Welfare (1986) produced Puao te Ata $t u$, a seminal report maintaining the existence of significant levels of racism in New Zealand society. In particular, this report drew attention to institutional racism, which it describes as "the outcome of monocultural institutions which simply ignore and freeze out the cultures of those who do not belong to the majority" (Ministerial Advisory Committee, 1986, p. 19). The authors looked to the overrepresentation of Māori in many of this country's negative social statistics to support their claim for the endurance of this form of racism in New Zealand. The report traced the failure of Aotearoa New Zealand's institutions to cater to the needs of many Māori back to the colonisation of this country. Māori, like other indigenous populations around the world, were marginalised through colonisation. In this country, the imposition of a European economic and legal system led to transfers of land from Māori into Pākehā ownership, and impoverishment for Māori. The impact of this, the authors claim, was far reaching and has led to ongoing material deprivation for many Māori.

The legacy of colonisation has meant Māori have a long history of experiencing prejudice in New Zealand. The racialisation of the Pasifika population as problematic has occurred relatively more recently. While Pasifika people migrated to New Zealand at different times depending on the formal arrangements various Pacific nations had with New Zealand (Humpage, 2012), many made the decision to come to New Zealand during a period of economic expansion during the 1960s and early 1970s when the demand for unskilled labour was high. In 1974, a change in the enforcement of immigration policy was introduced as the result of an economic downturn. Pasifika people, whose overstayer work permit status had previously been ignored, were targeted by an operation to expel them from New Zealand shores. This operation, known as the "dawn raids", ignored high numbers of non-Pasifika immigrant over-stayers, instead problematising the Pasifika population as the cause of rising unemployment. The racialisation of immigration policy escalated during the build-up to the 1975 general election, when the National Party specifically focused on Pasifika people in their anti-immigration campaign (Macpherson, 2006). Although the Pasifika population in New Zealand was established as a result of migration, today the majority of those identifying as Pasifika were born in this country (Tanielu \& Johnson, 2014). Commentators have argued, however, that the negative categorisation of Pasifika people is now entrenched in the fabric of Aotearoa New Zealand society and that racism shapes the social and economic experiences of Pasifika people in this country in much the same way as it does for Māori (Curtis \& Curtis, 2015; Tanielu \& Johnson, 2014). 


\section{Welfare, ethnicity and "social value"}

Like the authors of Puao te Ata tu (Ministerial Advisory Committee, 1986), other writers have argued that contemporary racist discourses are both grounded in, and continue to maintain, practices of colonisation. Wetherell and Potter (1992) propose that Pākehā make sense of colonial history in ways that reinforce contemporary racial prejudice. This prejudice, they contend, is well established in everyday discourse such as casual conversations and media reports. Through a detailed media analysis, Colvin (2008) similarly argues that historical racist discourses have developed into an established language for describing Māori in mainstream media. Tuffin's (2008) analysis of "race talk" amongst the dominant white majority in New Zealand also notes the endurance of discourses that, he argues, reinforce racism in this country.

Our discussion is framed by the prevalence of discourses linking ethnicity to the receipt of welfare for non-Pākehā lone mothers. Unmarried women who turn to the government for welfare support have long been constituted as problematic (Ferguson, 2013; Kingfisher \& Goldsmith, 2001; Longhurst, Hodgetts, \& Stolte, 2012; Patterson, 2004; Todd, 2008). Welfare is identified as the cause of social problems, rather than a solution, positioning lone mothers as immoral and bad parents. This discursive framing of welfare mothers resonates with the positioning of lone mothers in an international context (Edin \& Lein, 1997; Hancock, 2004; Hays, 2003; Jenson \& Tyler, 2015; Seccombe, 2007; Tyler, 2008). In a British context, Tyler (2008) argues that anti-welfare rhetoric directs feelings of anxiety and disgust towards welfare mothers amid concerns that such women are depleting public funds and raising problem children. New Zealand researchers have similarly identified discourses framing women on welfare as bad mothers, a drain on social resources (Ferguson, 2013; Kingfisher \& Goldsmith, 2001; Longhurst et al., 2012; Patterson, 2004; Todd, 2008) and sexually irresponsible (Uttley, 2000, p. 451).
The international literature has indicated that the intermingling of welfare discourses with discourses of race works to shape popular perceptions of poor women of colour (Dow, 2014; Hancock, 2004; Roschelle, 2013). In the United States, for example, negative depictions of poor black women have worked over time to produce the figure of the "welfare queen": a woman whose most prominent qualities are her rampant fertility, laziness and dishonesty (Hancock, 2004). Similarly, in Aotearoa New Zealand, beneficiaries who are not white have long been vilified in the popular imagination (Ministerial Advisory Committee, 1986). Beddoe (2014) has argued that the New Zealand media rely upon stigmatising and often highly racialised stereotypes of the poor, and particularly the welfare poor. Such depictions work to overshadow the structural inequalities that have led to disproportionate numbers of Māori and Pasifika claiming welfare (Beddoe, 2014). The welfare state has been re-imagined as nurturing welfare dependency, particularly amongst those who are not white.

Our findings are contextualised within notions of social value generated by the association of welfare with ethnicity. Skeggs' $(2004,2011)$ concept of person value is useful here in understanding the way that personhood is negotiated through social presentations that facilitate the identification of value. She argues that "systems of inscription, exchange, valuing, institutionalization and perspective provide the conditions of possibility for being read by others" (Skeggs, 2004, p. 2). Our analysis in this article emphasises the way participants experienced their ethnicity as impacting on their person value in the Work and Income environment. In our analysis, we focus on the way that participants described being "read" as non-Pākehā beneficiaries and their perception that this disadvantaged them during their visits to Work and Income. We consider the women's discussions of feeling out of place in the Work and Income environment, and their sense of being devalued and disadvantaged in this context. 


\section{Methods}

In 2014, the first author conducted 16 focus group interviews with 64 women throughout Aotearoa New Zealand. ${ }^{3}$ The women were all (or had recently been) receiving Sole Parent Support. Participants were recruited in a number of ways: through agencies providing support to lone mothers, through social networking sites aimed at lone mothers, and through a snowball technique. Twelve groups were held in Christchurch, two in Auckland, one in Wellington, and one in a small rural town that we have chosen not to name to ensure participant anonymity. The women were aged from 19 to 57 with the average age at the time of the interviews being 33 years. A total of 38 of the participants identified their ethnicity as Pākehā, 16 as Māori, seven identified with one or more Pasifika ethnicities, one woman identified as Indian, one as South American, and one as Asian.

When recruiting for the research, Māori and Pasifika women were offered the opportunity to take part in interviews with other Māori and Pasifika women. A number of women joined general groups but three Māori groups (14 participants) and three Pasifika interviews (five participants) took place. A Māori researcher facilitated the Māori groups, and a Pasifika co-facilitator assisted in the interviews with Pasifika women. These groups were organised in consultation with a cultural steering group (of which the second author was a member) and a Pasifika provider of health and social services to ensure that they were run in a culturally responsive way. In this article, we focus on the experiences of the 19 women who identified as Māori or Pasifika and who took part in these ethnicity-specific focus groups.

\section{Do your Pākehā friends have the same stories?}

The intention in running groups with Māori and Pasifika women was to engage with the similarities and differences pertaining to the lived experience of welfare amongst women of different ethnicities. In order to draw out these differences, a question was included to encourage the women to talk about their experiences of ethnicity in the welfare environment. This question manifested in the groups with Māori women as "so do your Pākehā friends have the same stories?" or "are there differences between Māori stories and non-Māori stories?"

Women in the three Māori groups reacted animatedly when asked about the differences between them and their Pākehā friends. The women all had stories to tell and often interrupted and spoke over one another in their enthusiasm to share. Their accounts were frequently filled with anger as many spoke of the perceived differences between their own experiences and those of the Pākehā welfare recipients they knew:

\section{Māori group (3)}

Danielle: I've got a friend, who is
on benefit with her kids,
she's Pākehā and she's had
no problems for the whole
four years she's been on
the benefit. Everything she
asks for she gets. Every time
she needs food grants she
gets it and she's never been
turned down for anything.
Then when I talk to my
Māori mates it's so different,
they're like, "bro they turned
me down. I've got to go to
Sallies ${ }^{4}$ and get a food grant"
and all this stuff, but she's
never had that problem,
ever and she's been on it for
four years. Her caseworker
is Pākehā too ... actually I
can say [my caseworker] is a
Māori, ... and he's amazing to
me whereas every other one I
had wasn't a Māori and they
weren't very nice.

In this excerpt, Danielle refers to Special Needs Grants. These are non-recoverable 
emergency payments and may be approved if someone has urgent costs and does not have the financial means to meet these. They are supplementary grants that all of the women were able to apply for in addition to their main benefit. Often the women interviewed had applied for them for food, and they were colloquially referred to as "food grants". As she related this story Danielle became irate. Her Pākehā friend has never had any problems with Work and Income "everything she asks for she gets." In contrast, her Māori friends are often declined in their applications for food grants. A number of other women, like Danielle, maintained that they were treated badly by Pākehā caseworkers and juxtaposed this with treatment by staff who were Māori. These women spoke about seeking out Māori or Pasifika caseworkers claiming that only then could they be sure that they would be treated fairly. The problem was, however, that the majority of caseworkers they had encountered were Pākehā. As Danielle points out, this has financial implications: Pākehā caseworkers are seen to be less likely to approve requests for additional assistance.

\section{Being Māori in a Pākehā environment}

During the discussions, the women proposed that the disadvantage they experienced was not simply the bias of individual Pākehā caseworkers, but was representative of the wider welfare environment. This was an environment that the women perceived as being dominated by Pākehā values and norms:

\section{Māori group (1)}

Kiri: Yeah. I've had friends that have worked there and still work there, and some will mihi ${ }^{5}$ to you across the office and they'll be like, "Hey, come over here." That would be so normal in any other setting but in that setting it's like I feel like I'm gonna get you fired. They're gonna cut my benefit. If I come and sit next to you they're gonna think that we're scheming something together or something like that. But it's so sad when you see your mates that work there and you can't really//

Hine: You don't feel like it's okay.

Kiri: / /You don't feel like it's okay to acknowledge one another. I'll be lucky if I get a [nod] from one of the people that I know that work there which sucks because out in the community it will be, "Oh, hey bro, how's kids", all that kind of thing. And they're not sitting there with a client; they're just sitting there typing. But it's like this unspoken rule that we don't know each other. We don't whakawhanaungatanga. ${ }^{6}$ We don't do what's normal for our culture. When we're inside those doors we keep our culture outside. And then when we come back out you can put your culture back on.

In this excerpt Kiri talks about encountering friends employed at Work and Income. Under other circumstances she would greet them and spend time talking but, in that context, she feels it is inappropriate. She is afraid that there will be repercussions in emphasising her ethnicity; "they're gonna think that we're scheming something together". Despite knowing Māori people employed by Work and Income it is clear that Kiri and Hine experience it as a Pākehā institution. For these women, the environment supports Pākehā cultural mores, encouraging certain ways of acting while discouraging others; "it's like this unspoken rule that we don't know each other", and as a result "we keep our culture outside". For Kiri and Hine, Māori culture has no place in the welfare setting.

While the women in one of the groups acknowledged Work and Income's efforts towards biculturalism, such as Māori signage and Māori and Samoan Language Weeks, these were derided as insincere: 


\section{Māori group (1)}

Kiri: $\quad$ But I bet when it comes to Māori Language week or Samoan language week [staff at Work and Income] are all up in their brown colleague's faces like//

Caitlin: Kia ora.

[Laughter]

Kiri: // Talofa. Thank you for your karakia. It really touched my heart. Just love our Māori people.

Kiri: What's a crack up is on the outside of the building it's got: $\mathrm{He}$ aha te mea nui o te ao? He tangata, he tangata, he tangata. What is the most important thing of this world? It is the people, it is the people, it is the people. Aaa [laughter] Lies.

Hine: Do you know what that means on your front [door]? [laughter].

The women's contempt for what they perceive to be a superficial engagement with Māori and Pasifika cultures aligns with Smith's (2012, p. 89) critique of a practice she has termed "trading the Other" in which indigenous culture is appropriated with "no concern for the peoples who originally produced the ideas or images". The Ministry of Social Development, like other Aotearoa New Zealand government departments, has made attempts to incorporate aspects of Māori culture into its spaces. Its website and the exterior of Work and Income buildings announce the institution's Māori name. Documents and signage within the offices commonly utilise Māori words and concepts. It is possible to speak to a staff member on the telephone in Māori using the multilingual line. The organisation has made efforts to increase the number of Māori and Pasifika staff employed. According to its website, $23 \%$ of staff are Māori and 13\% are Pasifika (Ministry of Social Development, n.d.). Yet
Kiri and Hine scorn the perfunctory attention paid to indigenous and minority cultures. The Ministry may employ non- Pākehā staff, it may endorse Māori and Samoan Language Weeks, and utilise a Māori proverb emphasising the worth of people on the outside of a building, but this does little to change their perception of Work and Income as a Pākehā institution.

\section{"It's hard for us. It's easy for the white people"}

The five Pasifika women who took part in the ethnicity specific discussions were interviewed in groups of two, and one woman was interviewed on her own. Three of the women - Tiresa, Rose and Lei - reported some particularly difficult interactions with Work and Income case managers that had made them reluctant to visit the offices. All three women spoke of being "scared" to go into Work and Income:

\section{Pasifika group (1)}

Tiresa: [At Work and Income] you would see heaps of faces and people make you scared. [laughs] I always scared when I enter Work and Income...

Rose: For me, I went to the Police Station one day. We went with Tiresa I wasn't even scared. But for the Work and Income [laughter] I was scared.

\section{Pasifika group (2)}

Lei: It's like a scary office [laughs] when you go over there. To be honest when I go there, I don't know if it's a good person or a bad person so how they talk. I think there's something they're not respect sometime when they keep asking questions because I didn't know they have the right to ask that one or not. 
The words "scared" (to describe themselves) or "scary" (to describe the Work and Income staff and environment) were repeated frequently in the interviews. The inevitability of poor treatment contributed to these feelings of anxiety making the women reluctant to ask for assistance. Of particular concern was the information asked for by caseworkers. As in Lei's account, the women often returned to the repetitive and intrusive questioning they faced from staff at Work and Income. Requests for personal information appeared to make them particularly uncomfortable. They were unsure of the purpose of the information requested, and why they were asked the same questions over and over again. The women queried the relevance of questions relating to their claims for entitlement, and so were uncertain if staff members "have the right to ask". This confusion appeared to provoke anxiety that they would inadvertently jeopardise their entitlements by misinterpreting or not being able to answer questions. These feelings were intensified by a perceived powerlessness in the Work and Income context, and an inability to negotiate with any of the caseworkers they had encountered in the past.

As in the groups with Māori women, during these interviews a question was included to encourage the women to talk about their experiences of being Pasifika in the welfare environment. This manifested as "do you ever think that Work and Income caseworkers treat you a certain way because you are not white?" or "do you feel that Pākehā friends on a benefit are treated differently?" Rose, Tiresa, and Lei were adamant that their ethnicity impacted on their engagement with their caseworkers:

\section{Pasifika group (1)}

Rose: It's hard for us. It's easy for the white people.

Tiresa: It's made me feel angry. What [Pākehā friends] say, "when we go there, we get everything like this". But what about me? When I go there, take ages to answer me, to give me the right answer. Then ... "come back the other week. Come back next week". But if my [Pākehā] friend go, it was like this [clicks fingers].

In the discussions, the women explained their difficult experiences entirely in terms of their ethnicity arguing that Pākehā caseworkers treated them a particular way because they were Pasifika people. In comments that resonated with Danielle's account above, Tiresa described her Pākehā friends receiving everything they ask for, but argued that Pasifika people must wait for weeks and sometimes still not receive a grant. When questioned further about this, Tiresa proposed that maybe she does not explain or talk "properly" or maybe it is because she was not born here. She was adamant, however, that for "Pasifika people, Island people" dealing with Work and Income is considerably more difficult.

\section{Intersecting Pasifika subjectivities}

A group interview with two other Pasifika women - May and Vailea - was markedly different. These women also recounted a number of challenging experiences with Work and Income. They spoke of feeling "belittled" and "devalued" during their visits to Work and Income, but both women were adamant that we were not treated differently from Pākehā people during the process of claiming their entitlements. When questioned about this Vailea replied, "I think it's more in how much education you have when you go in, so what you're entitled to, and how you're going to present your case."

The accounts of the five Pasifika women exemplify the way that multiple forms of disadvantage can intersect and shape experiences within the welfare context. Rose, Tiresa and Lei all spoke English as a second language, came from backgrounds marked with poverty, and had little family support around them. Two of the women had experienced violence in past relationships; 
one was the mother of seven children. May and Vailea came to the research from very different backgrounds. Both were tertiary educated, spoke English fluently and told of receiving support from their families. The women were also no longer receiving welfare. While May and Vailea recounted experiencing challenges in their dealings with Work and Income and acknowledged that there were problems with the system, environment and people at Work and Income, but they did not associate this with their ethnicity.

At the time of the interviews, May and Vailea were working very closely with marginalised Pasifika women. They described witnessing firsthand some of the difficulties their clients experienced in claiming welfare. Like Rose, Tiresa, and Lei, their clients struggled with English and with many of the questions asked by Work and Income staff. Vailea recounted seeing her clients being intimidated by questioning from Work and Income staff members and consequently becoming so anxious they could not provide the requisite information, nor ask for the assistance they needed. It was very clear, however, that these were not problems May and Vailea faced when negotiating with welfare caseworkers. Their ability to successfully navigate the welfare system meant these two women did not associate feelings of racial discrimination with the welfare environment.

\section{Discussion}

Feminist anti-racist theories consider the way that different categories of self intersect (Crenshaw, 1989, 1991; Mirchandani, 2003; Yuval-Davies, 2006). Inequality is seen as multidimensional where it is experienced and contested in shifting configurations. Considering the experiences of the Māori and Pasifika women who took part in the research emphasises the way that ethnicity intertwines with a number of intersecting social divisions such as gender, socioeconomic status, education, personal history, cultural context, and immigration status. Multiple forms of disadvantage can coalesce and impact the production of person value (Skeggs, 2004, 2011).

While all women spoke of feeling devalued by practices within the Work and Income context, May and Vailea's narratives emphasised a capacity to respond to these. Our analysis highlights that, in Aotearoa New Zealand, the social division of ethnicity needs to be considered as flexible and shifting rather than constitutive of encounters in the welfare context: discussions of ethnicity cannot be reduced to assumptions about similarities and differences. Above all, the analysis emphasises the complexity of accruing value in the welfare environment, and the way that this, in turn, can impinge on a person's capacity to access their entitlements.

While the analysis in this article emphasises that ethnicity cannot be understood as constitutive of interactions within the welfare environment, it is not our intention to imply that ethnicity does not impact on the way Māori and Pasifika women negotiate the Work and Income environment. Although not all of the Māori and Pasifika women spoke of their ethnicity disadvantaging them during their interactions at Work and Income, many of the women did frame their experiences in this way. May and Vailea's talk of successfully negotiating in this context stands in stark contrast with that of the other women who took part in the Māori and Pasifika groups. Rose, Tiresa, and Lei argued that Pākehā caseworkers treated them a particular way because they were Pasifika people. They, like a number of Māori participants, maintained that they were treated badly by Pākehā caseworkers. Hine spoke of imagining the thoughts of a caseworker who denied her a Special Needs Grant: "Oh, do I want to give to you? You look a little bit dark for my liking." Lei envisaged Work and Income staff thinking "the Islander no way no help." Tiresa conceded, "Maybe I'm not explain[ing] the right thing. Maybe I'm not talking properly. Maybe I'm not a Kiwi." These women 
spoke of seeking out Māori or Pasifika caseworkers claiming that only then could they be sure that they would be treated fairly. The problem was, however, that the majority of caseworkers encountered were Pākehā. There were financial implications to this: Pākehā caseworkers, it seems, not only "look at us differently" but, according to the women's accounts, were less inclined to approve requests for additional assistance.

The women's negative experiences in the Work and Income context were attributed to their not being Pākehā in an environment dominated by Pākehā caseworkers, values, and norms. Talk of differential treatment and of being out of place in a Pākehā environment emphasised the lack of value that the women felt accrued to them in the welfare context. The use of the word "value" aligns with Skeggs' $(2004,2011)$ notion of person-value referring to how, and under what conditions, value attaches to us (or not) in our relationships with others. Feeling devalued in the Work and Income context had much to do with the negative affect that not only attaches to the women as welfare mothers, but as non-Pākehā welfare mothers. The women seemed well aware of the practices that determine social value - good parenting, working, independence from the state - yet their accounts emphasised that they not only lack value because of their dependence on welfare, but that they embodied this lack through their ethnicity. It was the impossibility of distancing oneself from this perceived deficit that appeared to make the women's encounters at Work and Income so challenging.

There are significant implications in these research findings. The perception that a Pākehā woman will get "everything she asks for" while Māori and Pasifika women are declined assistance on the basis that they are "a little bit dark" appeared to influence the women's willingness to ask for the help that they needed. Many of the women spoke of a reluctance to visit Work and Income offices because of their past experiences thereby reducing the assistance to which they were entitled. Similarly, many participants in the broader research project that the ethnicity specific interviews were part of spoke of cutting their appointments short or going without necessities such as food rather than visiting offices to request this additional assistance (Gray, 2017). The analysis of the discussions with Māori and Pasifika women, however, suggests that anticipation of poor treatment was exacerbated by ethnicity particularly amongst women who also experienced disadvantage in other aspects of their lives. The expectation that they would be treated badly and declined assistance meant that Work and Income offices were hostile spaces that many of the Māori and Pasifika women who took part in the research would only enter when there was no other alternative - and sometimes not even then.

\section{Conclusion}

Our intention in this article has been to draw attention to accounts of Māori and Pasifika welfare lone mothers as they made sense of their experiences in the Work and Income context. Within this article we have considered the women's talk of feeling out of place in the Work and Income environment, and their sense of being disadvantaged by treatment in that context. Many of the Māori and Pasifika women argued that ethnicity influenced their experiences of welfare receipt and consequently impacted on their willingness to visit Work and Income. It appeared that the women who took part in the research not only had to contend with being constituted through welfare discourses that affect the experiences of all who rely on the state for support, but also with the racialisation of these discourses. In all of the Māori groups, participants claimed that racialised welfare discourse shaped their experiences of welfare receipt. Women in these groups also spoke of feeling out of place at Work and Income: an environment depicted as dominated by Pākehā values and beliefs. Similarly, three Pasifika participants described an affective atmosphere within Work and Income offices that made them 
feel very uncomfortable. They recounted the complexity of negotiating value within the welfare context where they were the embodiment of welfare dependency.

While we want to emphasise that women do not experience their ethnicity as a static identity, we contend that identifying as Māori or Pasifika may have implications in relation to the accessing of welfare. We argue that, in Aotearoa New Zealand, discourses of race have become fused with those of poverty thereby linking ethnicity to welfare dependency. Our analysis emphasises that the negative experiences associated with welfare receipt are amplified for non-Pākehā women in an environment where social and historical notions of value are associated with ethnicity. This is particularly concerning in light of the assertion made more than 30 years ago by the authors of Puao te Ata $t u$ that institutional racism impacted on the capacity of Māori welfare recipients to access their entitlements (Ministerial Advisory Committee on a Māori Perspective for the Department of Social Welfare, 1986). The findings from this research indicate that ethnicity still negatively influences interactions within welfare offices in New Zealand. We contend that, in Aotearoa New Zealand, racism frames the way that non-Pākehā lone mothers in poverty are perceived and impacts on their experience of welfare receipt.

\section{Notes}

${ }^{1}$ Pasifika is a term used in New Zealand to describe people who live in Aotearoa New Zealand and identify with the Pacific Islands and are therefore of Polynesian, Micronesian or Melanesian descent. The women we refer to as Pasifika in this article identified ethnically as Samoan and Tongan.

2 There is some concern that reported welfare figures for Pasifika people are not a true indication of need within this community. Several commentators have expressed a view that Pasifika people have a comparatively lower uptake of welfare benefits than other New Zealanders (Curtis \& Curtis, 2015; Tanielu \& Johnson, 2014) and that people may be under-claiming their entitlements (Curtis \& Curtis, 2015, p. 2).

${ }^{3}$ This research was approved by the University of Canterbury Human Ethics Committee (HEC 2014/12).

${ }^{4}$ Sallies refers to a food bank run by the Salvation Army.

${ }^{5}$ To mihi someone is to greet them (Moorfield, 2005).

${ }^{6}$ Whakawhanaungatanga translates as a process of establishing relationships with others (Moorfield, 2005).

\section{References}

Beddoe, L. (2014). Feral families, troubled families: The spectre of the underclass in New Zealand. New Zealand Sociology, 29(3), 51-68.

Colvin, G. (2008, September). The place of the native in the constitution of the white supremacy in New Zealand: A case study of settler press news stories about Maori. Paper presented at the Maori Research Symposium, University of Canterbury, Christchurch.

Crenshaw, K. (1989). Demarginalizing the intersection of race and sex: A black feminist critique of antidiscrimination doctrine. Feminist theory and antiracist politics. University of Chicago Legal Forum, 138-167.

Crenshaw, K. (1991). Mapping the margins: Intersectionality, identity politics, and violence against women of color. Stanford Law Review, 1241-1299.

Curtis, B., \& Curtis, T. (2015). The personal debt industry: Racist debt practices and Pasifika peoples in New Zealand. In S. M. Değirmencioğlu \& C. Walker (Eds.), Social and psychological dimensions of personal debt and the debt industry (pp. 268-287). Houndmills, Hampshire, England: Palgrave Macmillan. 
Dow, D. (2014). Negotiating "the welfare queen" and "the strong black woman": African American middle-class mothers' work and family perspectives. Sociological Perspectives, 58(1), 36-55.

Edin, K., \& Lein, L. (1997). Making ends meet: How single mothers survive welfare and low-wage work. New York, NY: Russell Sage Foundation.

Ferguson, J. (2013). The dream is over: The moral regulation of single mothers in New Zealand (Unpublished master's thesis). University of Auckland, Auckland, New Zealand. Retrieved from https: / / researchspace.auckland.ac.nz/ handle/2292/20202

Gray, C. (2017). A crying shame: Affect, emotion and welfare receipt in New Zealand (Unpublished doctoral thesis). University of Canterbury, Christchurch, New Zealand.

Hancock, A. (2004). The politics of disgust: The public identity of the welfare queen. New York, NY: New York University Press.

Hays, S. (2003). Flat broke with children. New York, NY: Oxford University Press.

Humpage, L. (2012). Understanding Maori and Pasifika attitudes towards employment and unemployed. New Zealand Sociology, 27(2), 29-53. Retrieved from http:/ / search. informit.com.au/documentSummary; $\mathrm{dn}=068776852928892$;res=IELHSS

Jensen, T., \& Tyler, I. (2015). "Benefits broods": The cultural and political crafting of antiwelfare commonsense. Critical Social Policy, 35(4), 470-491.

Kingfisher, C., \& Goldsmith, M. (2001). Reforming women in the United States and Aotearoa/New Zealand: A comparative ethnography of welfare reform in a global context. American Anthropologist, 103(3), 714-732.

Longhurst, R., Hodgetts, D., \& Stolte, O. (2012). Placing guilt and shame: Lone mothers' experiences of higher education in Aotearoa New Zealand. Social \& Cultural Geography, 13(3), 295-312.

Macpherson, C. (2006). Pacific peoples in Aotearoa/New Zealand: From sojourn to settlement. In K. Ferro (Ed.), Migration happens: Reasons, effects and opportunities of migration in the South Pacific (pp. 97-126). Piscataway, New Jersey: Transaction Publishers.

Marriott, L., \& Sim, D. (2015). Indicators of inequality for Māori and Pasifika people. Journal of New Zealand Studies, 20, 24-50.

Ministerial Advisory Committee on a Māori Perspective for the Department of Social Welfare. (1986). Puao te At tu (Daybreak). Wellington, New Zealand: Department of Social Welfare.

Ministry of Health. (2015). Tatau kahukura: Māori health chart book 2015 (3rd ed.). Wellington, New Zealand: Author.

Ministry of Social Development. (2017). Sole parent support - March 2017 quarter. Retrieved from https:/ /www.msd.govt. nz/documents/about-msd-and-ourwork/publications-resources/statistics / benefit/2017/sole-parent-support-benefitfact-sheet-mar-2017.doc

Mirchandani, K. (2003). Challenging racial silences in studies of emotion work: Contributions from anti-racist feminist theory. Organization Studies, 24(5), 721-742.

Moorfield, J. (2005). Te aka: Māori-English, English-Māori dictionary and index. Auckland, New Zealand: Pearson Education.

Pack, S., Tuffin, K., \& Lyons, A. (2016). Reducing racism against Maori in Aotearoa New Zealand. New Zealand Journal of Psychology, 45(3), 30-40.

Patterson, G. (2004). Women, mothers and citizens: Lone mothers' narratives in the context of New Zealand welfare reform (Unpublished doctoral thesis). University of Victoria, 
Wellington, New Zealand). Retrieved from http:/ / researcharchive.vuw.ac.nz/ handle/10063/582

Roschelle, A. (2013). "Why do you think we don't get married?" Homeless mothers in San Francisco speak out about having children outside of marriage. Advances in Gender Research, 17, 89-111.

Seccombe, K. (2007). So you think I drive a Cadillac? (2nd ed.). Boston, MA: Pearson Allyn \& Bacon.

Skeggs, B. (2004). Class, Self, Culture. London: Routledge.

Skeggs, B. (2011). Imagining personhood differently: person value and autonomist working-class value practices. The Sociological Review, 59(3), 496-513.

Smith, L. (2012). Decolonizing methodologies: Research and indigenous peoples. ( $\left.2^{\text {nd }} \mathrm{ed}\right)$. New York, NY: Zed books.

Statistics New Zealand. (2012). Working together: Racial discrimination in New Zealand. Retrieved from http://www. stats.govt.nz/browse_for_stats/people_ and_communities/asian-peoples/racialdiscrimination-in-nz.aspx

Statistics New Zealand. (2014). 2013 Census: Quick stats about culture and identity. Retrieved from http://www.stats.govt.nz/ Census /2013-census/profile-and-summaryreports/quickstats-culture-identity/pacificpeoples.aspx

Tanielu, T., \& Johnson, A. (2014). This is home: An update on the state of Pasifika people in New Zealand. Manukau, New Zealand: The Salvation Army Social Policy and Parliamentary Unit.

Todd, C. (2008). Political discourse and the domestic purposes benefit (Unpublished master's thesis). University of Auckland, Auckland, New Zealand.
Tuffin, K. (2008). Racist discourse in Australasia: Reviewing the last 20 years. Social and Personality Psychology Compass, 2(2), 591-607.

Tyler, I. (2008). "Chav mum chav scum." Class disgust in contemporary Britain. Feminist Media Studies, 8(1), 17-34.

Uttley, S. (2000). Lone mothers and policy discourse in New Zealand. Journal of Social Policy, 29(3), 441-458.

Wetherell, M., \& Potter, J. (1992). Mapping the language of racism: Discourse and the legitimation of exploitation. New York, NY: Columbia University Press.

Yuval-Davis, N. (2006). Intersectionality and feminist politics. European Journal of Women's Studies, 13(3), 193-209. 